\title{
Alkylation of Nitrogen-Containing Heterocycles via In Situ Sulfonyl Transfer
}

\author{
Jane Panteleev* \\ Robert J. Maguire \\ Daniel W. Kung \\ Synlett 2015, 26, 953.
}

Following publication of our work, we became aware of additional references that were not included in the original manuscript:

(14) Kurkin, A. V.; Karchava, A. V.; Yurovskaya, M. A. Chem. Heterocycl. Compd., 2000, 36, 1141.

(15) Soltani Rad, M. N.; Behrouz, S.; Najafi, H. Synthesis 2014, 46, 1380. 